\title{
Avaliação da oxidação de óleos, gorduras e azeites comestíveis em processo de fritura
}

\author{
Oxidative evaluation of oils, fats and edible oil in frying process
}

Heloisa Correia Sarmento Rios ${ }^{1}$, Isabela Rosier Olímpio Pereira ${ }^{2}$, Edeli Simioni de Abreu ${ }^{3}$

\section{RESUMO}

Objetivo: Avaliar a oxidação e a estabilidade de óleos e azeites utilizados na fritura. Foram determinados os índices de acidez, peróxido, iodo, refração e oxidação.

Materiais e Métodos: Os experimentos foram conduzidos com frituras de batatas durante 20 e $45 \mathrm{~min}\left(180^{\circ} \mathrm{C}\right)$ empregando os óleos de girassol (OG), milho (OM), óleo de canola (OC), soja (OS), os azeites de oliva (AO) e extra virgem (AOEV) e as gorduras de palma (GP) e vegetal hidrogenada (GVH). Os dados foram analisados utilizando-se uma análise de variância seguida do pós-teste de Tukey.

Resultados: OG, GVH e OS apresentaram maior alteração de acidez após 20 e 45 min de fritura, porém manteve-se de acordo com a legislação permitida para estes e os outros óleos, exceto AOEV. OC, OS e GP apresentaram maior alteração no índice de peróxidos após 20 e 45 min de fritura, estando adequados pela legislação. Para índice de iodo, OG, OS e AOEV estão ajustados à margem de oxidação permitida. OC, OS, GP e GVH tiveram redução esperada deste índice após fritura, devido à quebra das ligações resultante da oxidação. Todas as amostras analisadas exibiram índices de refração na faixa permitida pela legislação que não se alteram com a fritura. OC, OG, OS, AO e AOEV apresentaram maior oxidação e GP apresentou a menor oxidação.

Conclusão: Os óleos/gorduras com maior conteúdo de ácidos graxos saturados (GP) são mais estáveis que os óleos/gorduras contendo maior teor de ácidos graxos insaturados (OS, OG, OM). A adição de antioxidante pode refrear a oxidação, como observado com a GP.

Palavras-chave: análise de alimentos; óleos, gorduras; oxidação.

\begin{abstract}
Objective: To evaluate the oxidation and stability of oils used in the frying process. The following indexes were determined: acidity, peroxide, iodine, refraction and oxidation.

Materials and Methods: The experiments were conducted using sliced potatoes that were fried in sunflower oil (OG), corn oil (OM), canola (OC), soybean oil (OS), olive oil (AO), pure olive oil (AOEV), palm fat (GP) and hydrogenated vegetable fat $(G V H)$. Data were analyzed using an analysis of variance followed by the post hoc Tukey test.

Results: OG, GVH and OS showed higher acidity than other oils after 20 and 45 min of frying, however all values were in accordance with the legal parameters. The OC, OS and GP oils resulted in greatest change in the peroxide index after 20 and 45 min of frying time, being adequate to the legislation. As for the iodine index, the OG, OS, and AOEV are in accordance with the legal parameters. OC, OS, GP and GVH showed an expected decrease in the iodine index after the frying time, due the breakup of links as a result of the oxidation. All samples showed refractive index in accordance with the legal parameters and the values did not change with the frying process. OC, OG, OS, AO and AOEV have shown increased oxidation and GP showed an oxidation decrease.

Conclusions: Oils that contain more saturated fatty acids (GP) presented higher stability than the oils with unsaturated fatty acids compounds (OS, OG, OM). It was also noticed in the GP that the addition of antioxidants may decrease the oxidation.
\end{abstract}

Keywords: food analysis; oil; fat; oxidation.

\footnotetext{
${ }^{1}$ Farmacêutica graduada pela Universidade Presbiteriana Mackenzie, São Paulo.

${ }^{2}$ Farmacêutica. Doutora em Ciências dos Alimentos pela Faculdade de Ciências Farmacêuticas da USP. Professora do Curso de Farmácia e Nutrição da Universidade Presbiteriana Mackenzie, São Paulo.

${ }^{3}$ Nutricionista. Doutora em Saúde Pública pela Faculdade de Saúde Pública da USP. Professora do Curso de Farmácia e Nutrição da Universidade Presbiteriana Mackenzie, São Paulo.
} 


\section{INTRODUÇÃo}

A modernidade fez com que a procura por produtos alimentícios de fácil obtenção e de rápido procedimento aumentasse nos últimos tempos. A fritura é um desses processos que pode fornecer alimentos de preparo fácil e rápido, além de proporcionar sabor, odor e textura agradáveis para o consumidor ${ }^{1}$. A agilidade do processo e o resultado prazeroso é um requisito muito importante em relação aos produtos fritos, porém, devem-se levar em conta diversos fatores que podem alterar esses alimentos, podendo torná-los assim prejudiciais à saúde ${ }^{2-4}$.

Os óleos, gorduras e azeites são utilizados como meio de transferência de calor para que a fritura tenha um resultado desejável. Estes produtos são lipídeos, geralmente de origem vegetal, chamados de triacilgliceróis e são compostos por diversos ácidos graxos saturados e/ou insaturados ${ }^{4}$. Os óleos e gorduras são substâncias de origem animal ou vegetal, insolúveis em água (hidrofóbicas), formados predominantemente por ésteres de triacilgliceróis ${ }^{4}$. Os triacilgliceróis são produtos resultantes da esterificação entre o glicerol (cujo nome oficial da IUPAC é 1,2,3propanotriol) e até três moléculas de ácidos graxos saturados e/ou insaturados ${ }^{5,6}$. Além de triacilgliceróis, os óleos podem conter vários componentes em menor proporção, como mono e diglicerídeos; ácidos graxos livres; tocoferol (importante antioxidante); proteínas, esteróis e vitaminas ${ }^{4}$.

A diferença na composição e no grau de insaturação dos ácidos graxos presentes nos óleos e gorduras pode alterar as suas qualidades físico-químicas, além de favorecer ou diminuir as alterações químicas sofridas durante o processo, armazenamento e preparo desses produtos $^{7}$. São diversas as alterações que podem acometer os lipídeos sendo a oxidação a mais frequente. A oxidação pode ser favorecida por fatores internos e externos, como luz, presença de metais, calor, contato com oxigênio, entre outros ${ }^{5}$.

No processo de fritura os óleos sofrem ação tanto da temperatura quanto de oxigênio do ar. Estes fatores provocam reações extremamente complexas, originando peróxidos que se decompõem em produtos secundários (aldeídos, alcoóis, cetonas e hidrocarbonetos) responsáveis pela coloração, sabor e odor característico de um óleo oxidado ${ }^{8}$. O processo de fritura é uma operação usada principalmente para alterar a qualidade sensorial de um alimento, na qual se observa um processo simultâneo de transferência de calor e massa. O óleo de cozinha é usado como meio de transferência de calor para outro produto alimentício. Portanto, envolve tanto o efeito no óleo, que, por sua vez, influencia na qualidade do alimento, quanto 0 efeito direto do calor no produto frito ${ }^{2,4,9}$. Os produtos submetidos ao processo de fritura adquirem características organolépticas como cor, sabor, odor e textura agradáveis e desejáveis por diferentes grupos populacionais ${ }^{1,10,11}$. Na fritura por imersão em gordura, 0 produto é submerso no óleo/gordura e aquecido na presença de oxigênio. Portanto, o óleo/gordura é exposto à ação da umidade oriunda do alimento, ao oxigênio da atmosfera e à temperatura elevada ${ }^{1,11}$.

Além de proporcionar características sensoriais agradáveis aos alimentos o processo de fritura em altas temperaturas promove alterações oxidativas e químicas no óleo/gordura, caracterizadas por diminuição da insaturação total e aumento de teor de ácidos graxos livres, presença de espuma, coloração (escurecimento do óleo), aumento da viscosidade, substâncias polares e poliméricas ${ }^{1,3,4}$. Segundo Fellows ${ }^{9}$, os principais fatores que controlam as mudanças de cor e sabor em um dado alimento são: o tipo de óleo usado para fritura; a idade e a história térmica do óleo; a tensão interfacial entre o óleo e o produto; a temperatura e o tempo de fritura; o tamanho, teor de umidade e as características da superfície do alimento; e os tratamentos pós-fritura.

A ingestão de óleos, principalmente aqueles que contêm ácidos graxos essenciais (não sintetizados pelo organismo), além de ter palatabilidade agradável, é necessária para o organismo. Porém, o consumo excessivo de óleos bem como a ingestão desses produtos degradados pode trazer malefícios ao organismo como o risco de doenças cardíacas causadas pelo aumento do colesterol, o acometimento de aterosclerose e ainda pode favorecer a carcinogênese $^{2}$. Os lipídeos podem sofrer diversas alterações durante sua produção, processamento, preservação, armazenamento e durante o preparo do 
alimento propriamente dito. Essas alterações podem ser decorrentes de reações como oxidação, hidrólise, polimerização, pirólise, e absorção de sabores e odores estranhos ("off flavors") 2. Dentre esses fatores, a oxidação é a principal causa de degradação lipídica e pode levar à alteração de diversas propriedades dos óleos e dos próprios alimentos, como qualidades sensoriais (sabor, aroma, textura e cor), nutricionais, funcionais e toxide $z^{12}$.

Neste contexto, avaliar o tempo para o descarte e o grau de oxidação destes produtos pode contribuir para o estabelecimento de práticas saudáveis na utilização do processo de fritura, bem como, dos lipídeos utilizados neste processo. Existe hoje um amplo número de análises capazes de identificar o grau de oxidação de um óleo, que podem determinar a presença de peróxidos, fornecer a existência dos produtos secundários como os aldeídos ou ainda quantificar o número de ácidos graxos livres bem como o grau de acidez por eles provocado, entre outras determinações analíticas que auxiliam na detecção da oxidação lipídica. Assim, o presente estudo teve por objetivo avaliar a oxidação de óleos, gorduras e azeites comestíveis submetidos ao processo de fritura e comparar os resultados obtidos com a legislação vigente.

\section{MATERIAIS E MÉTODOS}

O objeto de estudo foi constituído por óleos, gorduras e azeites comumente utilizados para processos de cocção sob fritura. Para a realização dos ensaios de fritura de batatas palito congeladas, foram utilizadas amostras de quatro tipos de óleos, dois tipos de gorduras e dois tipos de azeites, adquiridas no comércio local, exceto a gordura de Palma cedida pela Indústria Agropalma®. Os produtos utilizados foram: Óleo de Canola (OC); Óleo de Girassol (OG); Óleo de Milho (OM); Óleo de Soja (OS); Gordura vegetal hidrogenada (GVH); Gordura de Palma (GP); Azeite de Oliva (AO mistura de azeite de oliva refinado e extra virgem); Azeite de Oliva extra virgem (AOEV); Batata Palito préfrita congelada McCain $\AA$.

A coleta de dados foi realizada no período de novembro de 2008 a janeiro de 2009 e foi efetuada diariamente por 4 semanas. As determinações analíticas foram realizadas em duplicata, concomitantemente para todas as amostras. Os procedimentos de fritura foram realizados na cozinha experimental da Universidade Presbiteriana Mackenzie. Os ensaios de fritura por imersão foram conduzidos em panela de aço inoxidável com capacidade aproximada de 2,5 litros e em fogão semi-industrial, com $500 \mathrm{~mL}$ de óleos, gorduras ou azeites. A temperatura empregada foi em torno de $180^{\circ} \mathrm{C} \pm 10^{\circ} \mathrm{C}$, controlada por termômetro laboratorial.

A relação superfície/volume calculada inicialmente e após a realização das frituras para cada amostra é indicada a seguir. Essa relação foi calculada dividindose a área superficial do óleo em contato com o ar atmosférico dentro do recipiente pelo volume do óleo utilizado em cada ensaio ${ }^{13}$ : todas as amostras - relação S/V Inicial $\left(\mathrm{cm}^{-1}\right)=0,2244$; amostras OC, OS, GP, GVH, AO e AOEV - relação S/V Final $\left(\mathrm{cm}^{-1}\right)=0,3530$; amostras OG e OM - relação S/V Final $\left(\mathrm{cm}^{-}{ }^{1}\right)=0,3272$.

Antes de iniciar a fritura, os óleos foram submetidos ao aquecimento por 10 minutos aproximadamente para que a temperatura de $180^{\circ} \mathrm{C}$ fosse alcançada uniformemente. $\mathrm{O}$ tempo entre cada $100 \mathrm{~g}$ de batata frita foi de aproximadamente 7 minutos, tempo suficiente para o estabelecimento da temperatura. $O$ tempo total de aquecimento para cada tipo de óleo foi de 45 minutos sem reposição do mesmo.

Foram coletados $100 \mathrm{~mL}$ das amostras, em recipientes plásticos devidamente encapados com folha de alumínio e denominadas de T0, T0', T1, T2 e T3. Adicionou-se 1 $\mathrm{mL}$ de BHT (Hidroxibutiltolueno) $5 \mathrm{mM}$ em cada amostra e após o resfriamento as amostras foram armazenadas à temperatura de aproximadamente $-20^{\circ} \mathrm{C}$. As amostras foram descongeladas no momento das análises. $O$ fluxograma, explicando a forma de coleta das amostras, é apresentado na figura 1.

As análises químicas e físicas foram conduzidas pelas seguintes metodologias: índice de acidez expressos em $\mathrm{mgKOH} / \mathrm{g}$ e \% p/p em ácido oléico, Ca $5 \mathrm{a}-40^{14}$; índice de peróxidos expressos em meq/kg de óleo, AOCS Cd 8-53 ${ }^{14}$; índice de iodo (Wijs), Normas Analíticas do Instituto Adolfo $\mathrm{Lutz}^{15}$; índice de refração mediante Refratômetro de Abbe, metodologia proposta por Moretto $^{5}$; detecção de aldeídos - reação de Kreis, Normas Analíticas do Instituto Adolfo Lutz ${ }^{15}$. 


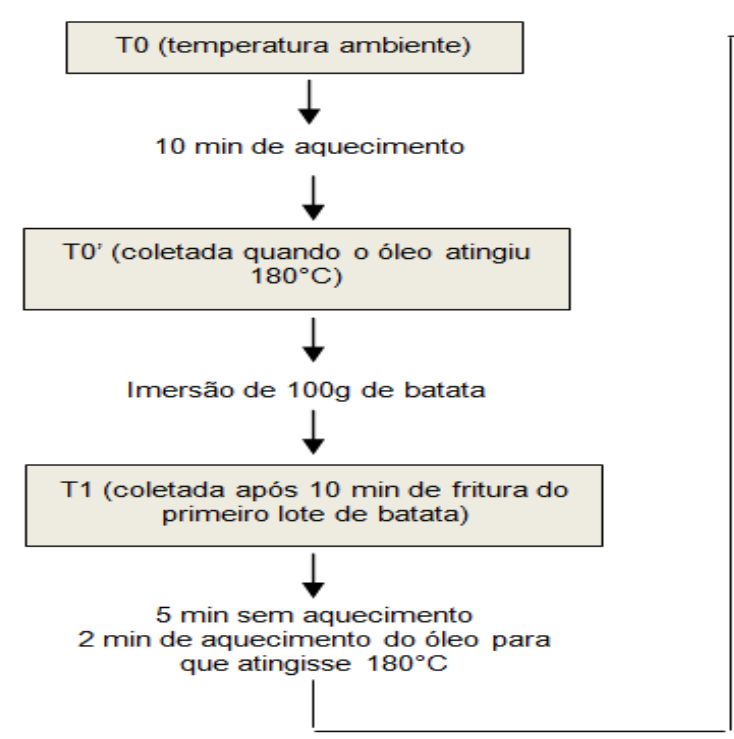

FIGURA 1 - Fluxograma de coleta das amostras analisadas.

Os valores obtidos nas análises foram comparados com os valores limites preconizados pela ANVISA, órgão responsável pelo regulamento técnico para óleos, gorduras e cremes vegetais no Brasil, através da Resolução $n^{\circ} \cdot 270^{16}$ e da Resolução $n^{\circ} \cdot 482^{17}$, e pelo Codex Alimentarius, fórum internacional responsável pela normalização sobre alimentos através do Stan$210^{18}$ e Stan-33 ${ }^{19}$.

As legislações utilizadas para comparação de cada análise e amostra estão relacionadas a seguir:

Legislação para Índice de acidez e Índice de peróxido

Amostras OC, OG, OM e OS - RDC $n^{\circ} 270$, Codex Alimentarius Stan-210; amostras GP e GVH - RDC $n^{\circ}$ 270; amostras AO e AOEV - RDC $n^{\circ} 270$, Codex Alimentarius Stan-33.

\section{Legislação para Índice de lodo e Índice de Refração}

Amostras OC, OG, OM, OS e GP - RDC n 482; amostra GVH - Sem parâmetros; amostras AO e AOEV - RDC n 482, Codex Alimentarius Stan-33.

A seguir são elucidados os parâmetros utilizados para comparar os resultados dos índices de acidez, peróxido, iodo e refração de acordo com as legislações citadas acima.

Valores máximos permitidos para o índice de acidez ${ }^{16-19}$

Amostras OC, OG, OM, OS, GP e GVH- valor máximo permitido: 0,6mg $\mathrm{KOH} / \mathrm{g}$; amostra $\mathrm{AO}$ - valor máximo permitido: 1,0g/100g em ácido oléico; amostra AOEV valor máximo permitido: $0,8 \mathrm{~g} / 100 \mathrm{~g}$ em ácido oléico.

Valores máximos permitidos para o índice de iodo $(\text { Wijs })^{17,19}$

Amostra OC - valor máximo permitido: 110-126; amostra OG - valor máximo permitido: 110-143; amostra OM - valor máximo permitido: 103-128; amostra OS - valor máximo permitido: 120-143; amostra GP - valor máximo permitido: 50-60; amostra GVH valor máximo permitido: Sem parâmetros; amostras $A O$ e AOEV - valor máximo permitido: 75-94.

Valores máximos permitidos para o índice de peróxido ${ }^{16-19}$

Amostras OC OG OM OS GP e GVH - valor máximo permitido: $10 \mathrm{meq} / \mathrm{Kg}$; amostra $A O$ - valor máximo permitido: $15 \mathrm{meq} / \mathrm{Kg}$; amostra AOEV - valor máximo permitido: $20 \mathrm{meq} / \mathrm{Kg}$.

Valores máximos permitidos para o índice de refração ${ }^{17,19}$

Amostra OC - valor máximo permitido: 1,465-1,467 (n $\left.D^{40}\right)$; amostra OG - valor máximo permitido: 1,465-1,469 $\left(n \mathrm{D}^{40}\right)$; amostra OM - valor máximo permitido: 1,4651,468 (n $\mathrm{D}^{40}$ ); amostra OS - valor máximo permitido: 1,466-1,470 (n $D^{40}$ ); amostra GP - valor máximo permitido: 1,454-1,456 (n $\mathrm{D}^{50}$ ); amostra GVH- Valor máximo permitido: Sem parâmetros; amostras 
TABELA 1 - Distribuição da média do índice de acidez, índice de peróxido, índice de iodo e índice de refração das amostras de óleos, gorduras e azeites estudados.

\begin{tabular}{|c|c|c|c|c|c|c|c|c|}
\hline \multirow[b]{2}{*}{ Tempo } & \multicolumn{6}{|c|}{ Índice de Acidez (mg KOH/ 1g óleo) } & \multicolumn{2}{|c|}{ (g ác. oléico/100g óleo) } \\
\hline & OC & OG & OM & os & GP & GVH & AOEV & AO \\
\hline T0 & 0,14433 & 0,09154 & 0,17809 & 0,23600 & 0,17480 & 0,14385 & 1,53690 & 0,67649 \\
\hline Tо' & 0,20265 & 0,11078 & 0,21355 & 0,29285 & 0,17776 & 0,13681 & 1,53841 & 0,68766 \\
\hline T1 & 0,20206 & 0,13639 & 0,22307 & 0,34574 & 0,18300 & 0,19988 & 1,54704 & 0,70802 \\
\hline T2 & 0,22412 & 0,16954 & 0,24637 & 0,38487 & 0,21495 & 0,23558 & 1,60513 & 0,73363 \\
\hline T3 & 0,29737 & 0,23092 & 0,28082 & 0,44396 & 0,29663 & 0,26453 & 1,63584 & 0,75545 \\
\hline \multicolumn{9}{|c|}{ Índice de Peróxido (meq/Kg) } \\
\hline Tempo & OC & OG & OM & os & GP & GVH & AOEV & AO \\
\hline T0 & 0,69489 & 2,91844 & 2,86590 & 1,38749 & 0,86784 & 9,24053 & 16,27036 & 10,09385 \\
\hline T0' & 2,98760 & 4,18907 & 3,34736 & 6,45131 & 1,04510 & 9,65927 & 17,84393 & 10,33998 \\
\hline T1 & 5,40428 & 4,67315 & 3,34202 & 7,94111 & 1,52163 & 5,39850 & 12,08368 & 10,02682 \\
\hline T2 & 6,58170 & 4,46996 & 4,21016 & 6,96692 & 2,20120 & 4,97038 & 10,47188 & 9,90804 \\
\hline T3 & 7,17018 & 5,08593 & 4,45425 & 9,95980 & 3,45414 & 6,04932 & 10,48194 & 11,38148 \\
\hline \multicolumn{9}{|c|}{ Índice de lodo (Wijs) } \\
\hline Tempo & OC & OG & $\mathrm{OM}$ & os & GP & GVH & AOEV & AO \\
\hline TO & 135,83226 & 138,65995 & 122,20601 & 141,59202 & 77,58518783 & 97,5420693 & 89,9267702 & 83,05056424 \\
\hline T1 & 128,09903 & 138,2963 & 136,59665 & 140,76044 & 70,23015696 & 96,8713655 & 90,4674814 & 93,45596471 \\
\hline \multirow[t]{2}{*}{ T3 } & 131,98039 & 140,98871 & 126,34032 & 138,49048 & 67,4264981 & 90,8407029 & 92,4533625 & 98,30197557 \\
\hline & \multicolumn{4}{|c|}{ Índice de Refração $\left(40^{\circ} \mathrm{C}\right)$} & \multicolumn{2}{|c|}{ Índice de Refração $\left(50^{\circ} \mathrm{C}\right)$} & \multicolumn{2}{|c|}{ Índice de Refração $\left(20^{\circ} \mathrm{C}\right)$} \\
\hline Tempo & OC & $O G$ & OM & os & GP & GVH & AOEV & AO \\
\hline TO & 1,46453 & 1,46663 & 1,46503 & 1,46653 & 1,45510 & 1,45820 & 1,46883 & 1,46833 \\
\hline Tо' & 1,46453 & 1,46663 & 1,46503 & 1,46653 & 1,45530 & 1,45820 & 1,46933 & 1,46833 \\
\hline T1 & 1,46453 & 1,46663 & 1,46503 & 1,46653 & 1,45530 & 1,45820 & 1,46933 & 1,46833 \\
\hline T2 & 1,46453 & 1,46663 & 1,46503 & 1,46653 & 1,45540 & 1,45820 & 1,46933 & 1,46833 \\
\hline T3 & 1,46453 & 1,46663 & 1,46503 & 1,46653 & 1,45560 & 1,45820 & 1,46953 & 1,46833 \\
\hline
\end{tabular}

Legenda: (OC) óleo de canola; (OG) óleo de girassol; (OM) óleo de milho; (OS) óleo de soja; (GP) gordura de palma (GVH) gordura vegetal hidrogenada; (AO) azeite de oliva e (AOEV); azeite de oliva extra virgem.

AO e AOEV - valor máximo permitido: 1,4677-1,4705 (n $\left.D^{20}\right)$.

Todos os valores foram expressos como média \pm EPM (erro padrão da média). As análises estatísticas foram realizadas utilizando o programa Sigma Stat Statistical V.3.1 (Sigma Stat Software Inc., Chicago, USA). Comparações entre os grupos experimentais foram analisadas por variância (ANOVA) e o pós-teste de Tukey foi utilizado para comparar os grupos individualmente. Valores de $p<0,05$ foram considerados significantes. Por não se tratar de pesquisa com seres humanos ou animais, mas sim com alimentos, não houve necessidade de aprovação por um comitê de ética.

\section{RESULTADOS}

Os resultados de cada análise a que cada amostra foi submetida são apresentados na tabela 1.

Índice de Acidez

O índice de acidez de todos os óleos, gorduras e o azeite de oliva (tabela 1) encontram-se de acordo com os requisitos máximos permitidos para o índice de acidez preconizado ${ }^{16-19}$. Exceto o azeite de oliva extra virgem que apresentou índice de acidez superior ao valor máximo permitido em todos os tempos, inclusive no T0 que não sofreu aquecimento. Calculou-se a porcentagem de alteração do índice de acidez do T1 em relação ao T0 e do T3 em relação ao T0 (figura 2) para todas as amostras. A porcentagem de alteração do T3 em relação ao T0 do óleo de girassol foi significativamente maior do que os dois tipos de azeite $(p<0,01)$. 


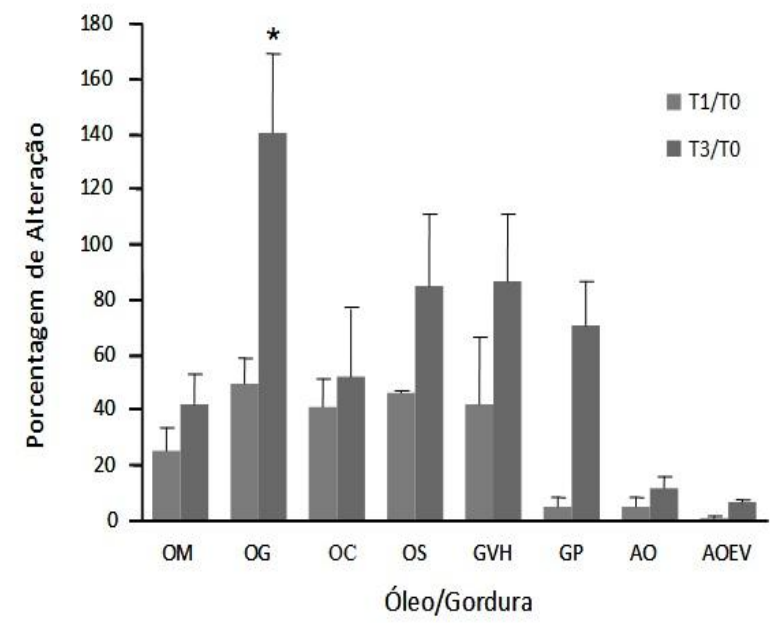

FIGURA 2 - Alteração do índice de acidez. OC: óleo de canola; OG: óleo de girassol; OM: óleo de milho; OS: óleo de soja; GP: gordura de palma; GVH: gordura vegetal hidrogenada; $A O$ : azeite de oliva; AOEV: azeite de oliva extra virgem. ${ }^{*} \mathrm{p}<0,01 \mathrm{x}$ AO, AOEV.

\section{Índice de peróxido}

Todas as amostras analisadas (tabela 1) permaneceram com índice de peróxidos inferior ao máximo permitido em todos os tempos ${ }^{16-19}$. A porcentagem de alteração do T1 em relação ao T0 e do T3 em relação ao T0 (figura 3) foi calculada para todas as amostras. O percentual de alteração do $\mathrm{T} 1 \mathrm{em}$ relação ao T0 e do T3 em relação ao T0 da canola e do óleo de soja foi significativamente maior que todos os demais óleos, gorduras e azeites analisados $(p<0,01)$.

\section{Índice de lodo}

Somente os óleos de girassol e soja e o azeite de oliva extra virgem obtiveram valores dentro da margem permitida pela resolução utilizada ${ }^{16-19}$. Os demais óleos, gorduras e azeite demonstraram valores muito discrepantes, oscilando em todos os tempos (tabela 1). O óleo de milho no $\mathrm{T} 1$ teve um resultado superior ao permitido. Canola e a gordura de palma tiveram, em todos os tempos analisados, valores superiores ao permitido. O azeite de oliva teve um resultado superior ao permitido somente no T3.

\section{Índice de Refração}

Somente a gordura de palma e o azeite de oliva extra virgem tiveram uma elevação no índice de refração, contudo, todos os resultados permaneceram dentro da faixa permitida ${ }^{16-19}$. A tabela 1 apresenta os valores

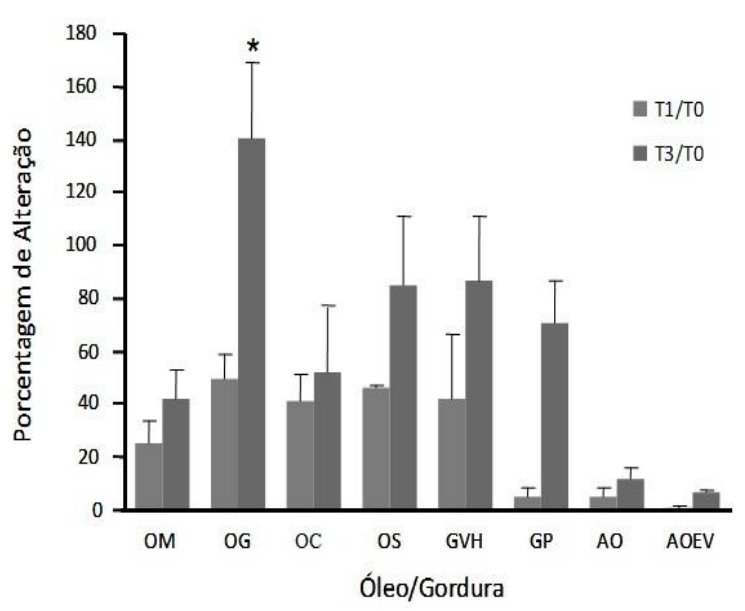

FIGURA 3 - Alteração de índice de peróxido. OC: óleo de canola; OG: óleo de girassol; OM: óleo de milho; OS: óleo de soja; GP: gordura de palma; GVH: gordura vegetal hidrogenada; $\mathrm{AO}$ : azeite de oliva; $\mathrm{AOEV}$ : azeite de oliva extra virgem. ${ }^{*} p<0,01 \times O M, O G, G V H, G P, A O, A O E V . \# p<0,01 \times$ OM, OG, GVH, GP, AO, AOEV.

encontrados de acordo com as temperaturas indicadas para a realização do teste.

\section{Reação de Kreis}

Como descrito anteriormente, esta análise foi realizada para todas as amostras em todos os tempos. Os resultados foram expressos por intensidade de coloração (tabela 2), segundo a ordem determinada na legenda.

\section{DISCUSSÃO}

Em alguns países como Alemanha, Bélgica, Estados Unidos, entre outros, existem normas estabelecidas para o descarte de óleos utilizados para fritura. Embora nacionalmente não exista legislação para a utilização desses óleos, o estado de São Paulo possui a CVS $6 / 99^{20}$, que estabelece a temperatura ideal de aquecimento para óleos e gorduras, o ponto de descarte e os testes recomendados para o controle de qualidade dos mesmos. Apesar de ter um alcance estadual, este regulamento técnico também é utilizado por outros estados, visando garantir a qualidade dos óleos e dos alimentos fritos $^{21,22}$.

As alterações de degradação sofridas pelo óleo em processo de aquecimento dependem de diversos fatores como o tipo de óleo, temperatura, relação superfície/volume, tipo de aquecimento e natureza do 
TABELA 2 - Intensidade de coloração obtida na Reação de Kreis de cada amostra.

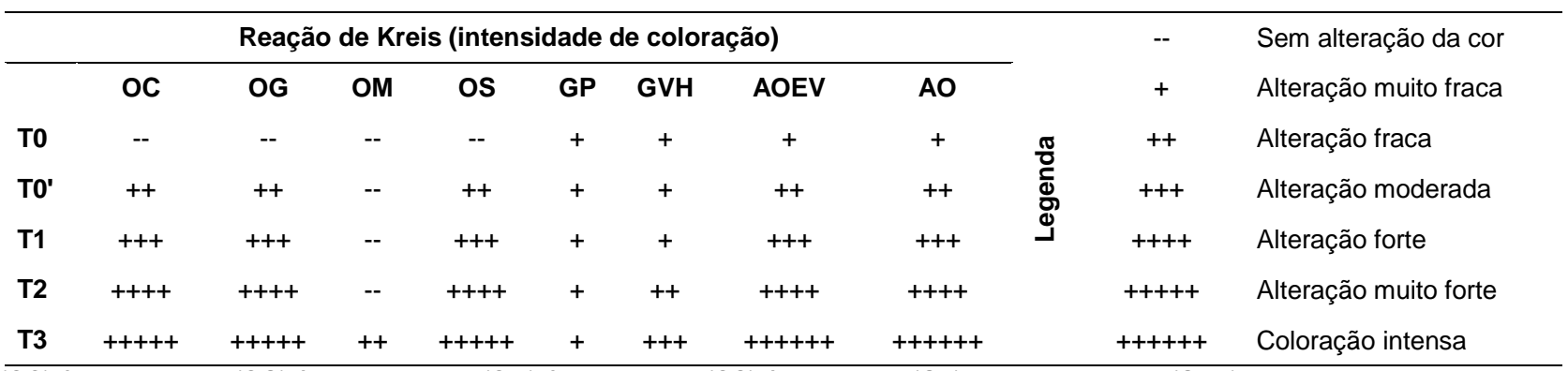

(OC) óleo de canola; (OG) óleo de girassol; (OM) óleo de milho; (OS) óleo de soja; (GP) gordura de palma (GVH) gordura vegetal hidrogenada; (AO) azeite de oliva e (AOEV); azeite de oliva extra virgem.

alimento. Essas alterações podem ser indicadas por métodos analíticos, que servem para identificação e avaliação da qualidade de óleos e gorduras ${ }^{13}$.

O índice de acidez é uma variável intimamente relacionada com a natureza, qualidade e o grau de pureza da gordura, com o processamento e, principalmente, com as condições de conservação da gordura $^{12}$. Há uma relação direta entre o aumento do número de frituras e maior hidrólise do óleo, devido à alta temperatura e à troca de umidade do alimento para o meio de fritura, com conseqüente aumento no conteúdo de ácidos graxos livres, que são os responsáveis pela elevação da acidez do óleo ${ }^{23}$.

Conforme a figura 2, o óleo que apresentou o maior percentual de alteração do índice de acidez, tanto do T1 em relação ao T0 quanto do T3 em relação ao T0, foi o óleo de girassol, seguido da gordura vegetal hidrogenada e do óleo de soja. Porém, tanto esses quanto as demais amostras, exceto o azeite de oliva extra virgem, apresentaram valores iniciais dentro do limite permitido ${ }^{16-19}$ e não excedem este limite mesmo com a elevação causada pela fritura, indicando que não houve um aumento significativo na acidez desses óleos.

Entretanto, o azeite de oliva extra virgem, apresentou um índice de acidez superior ao máximo permitido $(0,8 \mathrm{~g}$ de ácido oléico/100g de óleo), já no tempo inicial (sem aquecimento). Por este motivo, a marca registrada de todas as amostras utilizadas não foi indicada, já que este azeite se encontrava fora dos padrões preconizados pela legislação. De acordo com Masson et al. $^{24}$, a acidez livre encontrada no óleo não reflete apenas os ácidos graxos formados durante o processo de fritura, como também aqueles inicialmente presentes no óleo antes do aquecimento e os extraídos dos alimentos que estão sendo fritos. Portanto, o elevado grau de acidez inicial do azeite não indica sua degradação, visto que o aumento gradativo do índice não foi severo.

O índice de peróxido é um indicador do grau de oxidação do óleo ou gordura. Em relação à porcentagem de alteração do T1/T0 e do T3/T0, os óleos que apresentaram índice de peróxido mais alterado foram o óleo de canola e o óleo de soja, o que pode ser explicado pela composição de ácidos graxos de cada óleo. O óleo de soja, por conter maior quantidade de ácidos graxos insaturados do que saturados, é mais susceptível ao processo oxidativo ${ }^{25}$. Além disso, o índice de peróxido inicial destes dois óleos foram os mais baixos, portanto, suas alterações foram mais perceptíveis.

A gordura de palma, apesar de apresentar uma porcentagem de alteração do índice de peróxido mais alta que o da gordura vegetal, do óleo de milho, da canola e dos azeites, manifestou os menores índices de peróxidos em todos os tempos de fritura, resultado este, que pode ser atribuído ao seu maior grau de saturação.

Segundo alguns autores ${ }^{1,3,10}$, há uma limitação na metodologia para determinação de peróxidos; essas substâncias, por serem instáveis, são rapidamente formadas e fracionadas em moléculas menores, como aldeídos e cetonas, que mesmo presentes no óleo, nem sempre são detectadas pela análise. Este fato ocorre principalmente em tempos de fritura mais elevados, fazendo com que este índice não seja um bom indicador do estado de alteração do óleo, pois, a velocidade de degradação é maior que a velocidade de formação de peróxidos.

Outra técnica utilizada para detecção da degradação 
dos óleos é o índice de iodo. Este índice relaciona-se com a quantidade de duplas ligações presentes na amostra. Somente os óleos de girassol e soja e o azeite de oliva extra virgem obtiveram valores dentro da margem permitida pela resolução ${ }^{17}$. As demais amostras demonstraram uma oscilação muito grande. Apesar desta discrepância, o óleo de canola, o óleo de soja, a gordura de palma e a gordura vegetal apresentaram uma redução esperada deste índice devido, provavelmente, à quebra das duplas ligações resultante das reações de oxidação.

Segundo Moretto et al. ${ }^{5}$, quanto maior a insaturação de um ácido graxo, maior será a sua capacidade de absorção de iodo e, conseqüentemente, maior será o índice de iodo. Por esta razão, a gordura de palma apresenta o menor índice de iodo em comparação com os demais óleos e gorduras. Os óleos e gorduras possuem poderes de refringências diferentes $e$, de acordo com a sua natureza, desviam com maior ou menor intensidade os raios luminosos que os atravessam. O índice de refração é característico para cada tipo de óleo e está relacionado com o grau de insaturação dos ácidos graxos constituintes dos triglicerídeos, com 0 comprimento da cadeia hidrocarbonada e com o tratamento térmico ${ }^{13}$.

Todas as amostras analisadas exibiram índices de refração dentro da faixa permitida pela legislação ${ }^{16-19}$. Mesmo com o sutil aumento do índice de refração da gordura de palma e do azeite de oliva extra virgem, não é possível afirmar somente com este dado que esses óleos se alteraram. Nossos dados corroboram as observações de Varela et al. ${ }^{26}$, cujo estudo demonstrou que os valores para o índice de refração de alguns óleos vegetais (soja, oliva e girassol) utilizados em frituras repetidas, não apresentaram alterações ao longo do processo de fritura. Segundo estes mesmos autores, em geral, este índice não varia quando as condições experimentais são mais brandas.

Embora os resultados acima discutidos, não indicarem uma degradação muito expressiva das amostras estudadas, a canola, o óleo de girassol, soja, o azeite de oliva e o azeite de oliva extra virgem apresentaram positividade para a reação de Kreis, um procedimento qualitativo que indica os produtos secundários da oxidação de óleos e gorduras ${ }^{12}$.

Segundo este método, o azeite de oliva extra virgem apresentou a coloração mais intensa no tempo 3 e a gordura de palma a menos intensa. Este resultado juntamente com os outros obtidos, indica que o azeite de oliva extra virgem foi a amostra que sofreu uma maior alteração em relação aos demais, enquanto o óleo de milho e a gordura de palma os que sofreram menor alteração com o processo de fritura. Justifica-se esse dado pelo fato de que inicialmente o azeite já se apresentava fora dos padrões permitidos e com índices elevados mesmo nas amostras não submetidas ao aquecimento. A gordura de palma não manifestou degradação por ser composta de ácidos graxos saturados, que são mais estáveis do que os insaturados, e também devido à presença de antioxidantes adicionados no processo industrial

É importante ressaltar que, além dos fatores já mencionados como a elevada temperatura, o contato prolongado do oxigênio com o óleo, a incidência de luz, a presença de metais e o grau de insaturação dos óleos, a natureza do alimento é outro fator importante, capaz de comprometer a qualidade dos óleos utilizados no processo de cocção sob fritura ${ }^{1}$. Del-Ré \& Jorge ${ }^{22}$ utilizaram em seus estudos batata palito pré-frita congelada e produto cárneo empanado pré-frito congelado. Devido à quantidade de ácidos graxos saturados liberados no óleo durante a fritura do produto cárneo empanado, este apresentou uma estabilidade oxidativa maior. Cella et al. $^{23}$ pesquisaram 0 comportamento dos óleos em processo de fritura de produtos vegetais, comprovando que ao fritar alimentos com alto conteúdo de água intrínseca, e extrínseca oriunda do pré-preparo, poderá ocorrer um efeito deteriorativo ainda maior sobre o óleo ou gordura.

Esse estudo demonstrou que a maioria dos óleos analisados obtiveram resultados dentro dos parâmetros preconizados pela legislação, entretanto, o azeite de oliva extra virgem apresentou um índice de acidez inicialmente superior ao máximo permitido. $A$ degradação ocorrida durante o processo de fritura dos óleos estudados não foi expressiva, sendo necessário um aumento do tempo de fritura para que o aparecimento dessas alterações seja mais evidente. 
A partir das análises realizadas foi possível concluir que a gordura de palma e o óleo de milho são mais estáveis que os óleos/gorduras com maior teor de ácidos graxos insaturados, a saber, óleo de soja e girassol. Além disso, a adição de antioxidante no processo industrial pode refrear a oxidação, como ocorreu com a gordura de palma.

\section{REFERÊNCIAS}

1. Corsini MS, Jorge N. Estabilidade oxidativa de óleos vegetais utilizados em frituras de mandioca palito congelada. Ciên Tecnol Aliment. 2006;26:27-32.

2. Araújo JMA. Química de alimentos: teoria e prática. 3a. ed. rev. ampl. Viçosa (MG): UFV; 2004. 478 p

3. Damy PC, Jorge N. Determinações físico-químicas do óleo de sija e da gordura vegetal hidrogenada durante o processo de fritura descontínua. Braz J Food Technology 2003;6(2):251-7

4. Reda SY, Carneiro PIB. Óleos e gorduras: aplicações e implicações. Rev Analytica 2007;27:60-7.

5. Moretto E, Fett R, Gonzaga LV, Kuskoski EM. Introdução à ciência de alimentos. Florianópolis: Ed. da UFSC; 2002. $255 \mathrm{p}$.

6. Zambiazi RC, Przybylski R, Zambiazi MW, Mendonca CB. Fatty acid composition of vegetable oils and Fats. B Ceppa 2007;25(1):111-20.

7. Bobbio FO, Bobbio PA. Introdução à química de alimentos. 3a.ed. São Paulo: Varela; 2003. 238 p.

8. Jorge $\mathrm{N}$, Soares BBP, Lunardi VM, Malacrida CR. Alterações físico-químicas dos óleos de girassol, milho e soja em frituras. Quím Nova 2005; 28(6):947-51.

9. Fellows PJ. Tecnologia do processamento de alimentos:

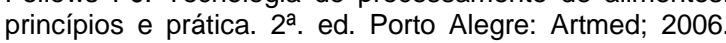
$602 \mathrm{p}$.

10. Sanibal EAA, Mancini Filho J. Alterações físicas, químicas e nutricionais de óleos submetidos ao processo de fritura. Food Ingredients South America 2002;18:48-54

11. Silva MR, Cerqueira FM, Silva PRM. Batatas fritas tipo palito e palha: absorção de gordura e aceitabilidade. Nutrire 2003; 26:51-62.

12. Moretto E, Fett R. Tecnologia de óleos e gorduras vegetais na indústria de alimentos. São Paulo: Varela; 1998. $150 \mathrm{p}$.

13. Malacrida $\mathrm{CR}$, Jorge $\mathrm{N}$. Influência da relação supervície/volume e do tempo de fritura... Ciênc Agrotec. 2006;30(4):724-30.

14. American Oil Chemists' Society (AOCS). Official methods and recommended practices of the American Oil Chemists Society. Champaign: AOCS; 1990.

15. Instituto Adolfo Lutz. Normas analíticas do Instituto Adolfo
Lutz. 3å. ed. São Paulo: Instituto Adolfo Lutz; 1985. 371 p.

16. Brasil. Resolução RDC ANVISA/MS $n^{\circ}$. 270, de 22 de setembro de 2005. Regulamento Técnico para óleos vegetais, gorduras vegetais e creme vegetal. Diário Oficial da União, Brasília, DF, 29 ago.; 2005. Seção 1.

17. Brasil. Resolução RDC ANVISA/MS n. 482, de 23 de setembro de 1999. Regulamento Técnico fixação de identidade e qualidade de óleos e gorduras vegetais. Diário Oficial da União, Brasília, DF, 22 set.; 1999. Seção 1.

18. World Health Organization. Codex Alimentarius Commission Joint WHO/FAO: Codex Stan 210 - 1999 (Rev. 2-2003) - Codex standard for named vegetable oils, Joint FAO/WHO Food Standards Programme. Geneve: WHO/FAO; 2003. p. 1-13.

19. World Health Organization Codex Alimentarius Commission Joint WHO/FAO, Codex Stan 33 - 1981 (Rev. 2-2003) - Codex standard for olive oils and olive pomace oils, Joint FAO/WHO Food Standards Programme. Geneve: WHO/FAO; 2003. p. 1-9.

20. São Paulo. Portaria CVS/MS n०. 6, de 10 de março de 1999. Regulamento Técnico, que estabelece os Parâmetros e Critérios para o Controle Higiênico-Sanitário em Estabelecimentos de Alimentos. Diário Oficial da União, Brasília, DF, 10 mar. 1999; Seção 1.

21. Ans VG, Mattos ES, Jorge N. Avaliação da qualidade dos óleos de fritura usados em restaurantes, lanchonetes e similares. Ciênc Tecnol Aliment. 1999;19(3):413-9.

22. Del-Ré, PV, Jorge N. Comportamento dos óleos de girassol, soja e milho em frituras de produto cárneo empanado pré-frito congelado. Ciênc Agrotec. 2007; 31(6):1774-9.

23. Cella RCF, Reginato-D'arce MAB, Spoto MHF. Comportamento do óleo de soja refinado utilizado em fritura por imersão com alimentos de origem vegetal. Ciênc Tecnol Aliment. 2002;22(2):111-6.

24. Masson L, Robert P, Romero N, Izaurieta M, Valenzuela $S$, Ortiz J, Dobarganes MC. Comportamiento de aceites poliinsaturados en la preparación de patatas fritas para consumo inmediato: Formación de nuevos compuestos y comparación de métodos analíticos. Grasas y Aceites 1997; 48(5):273-81.

25. Pinto EP, Borges CD, Teixeira AM, Zambiazi RZ. Características da batata frita em óleos com diferentes graus de insaturação. B Ceppa 2003;21(2):293-302.

26. Varela G, Moreiras-Varela O, Ruiz-Roso B. Utilización de algunos aceites em frituras repetidas. Câmbios em lãs grasas y análisis sensorial de los alimentos fritos. Grasas y Aceites 1983;34(2):101-7.

\section{Endereço para correspondência}

Edeli Simioni de Abreu

Alameda São Caetano $n^{\circ} 857$, apto. 43

São Caetano do Sul/SP - CEP 09560-105

Telefone: +55 11984349393

E-mail: edeli@mackenzie.com 